\title{
SEY OTTÓ ÉLETE ÉS MUNKÁSSÁGA
}

(Kapuvár, 1936. október 22 - Sopron, 2017. december 25.)

\section{Faragó Sándor}

Soproni Egyetem, Erdőmérnöki Kar, Vadgazdálkodási és Gerinces Állattani Intézet

University of Sopron, Faculty of Forestry, Institute of Wildlife Management and Vertebrate Zoology

H-9400 Sopron, Bajcsy-Zs u. 4., Hungary; e-mail: farago.sandor@uni-sopron.hu

\begin{abstract}
FARAGÓ S. (2019): OTTÓ SEY's (1936-2017) LIFE AND LIFE-WORK - AN OBITUARY. Hungarian Small Game Bulletin 14: 1-17. http://dx.doi.org/10.17243/mavk.2019.001

Prof. Dr. OTTÓ SEY, world-renowned Hungarian helminthologist, retired Professor of the University of Pécs, due to an unexpected disease, passed away on 25 December, 2017. His funeral was held on 4 January, 2018 in Kapuvár (Hungary). To honour the memory of Professor SEY, the paper presents an obituary recounting his career and his published scientific papers.
\end{abstract}

KULCSZAVAK: SEY OTTÓ, nekrológ

KEY WORDS: OTTÓ SEY, obituary

Türelemmel viselt hosszú betegség után 2017. december 25-én, életének 82. évében Sopronban elhunyt Prof. Dr. SEY OTTÓ nyugalmazott egyetemi tanár, a világhírü helmintológus, kiváló tudós, pedagógus.

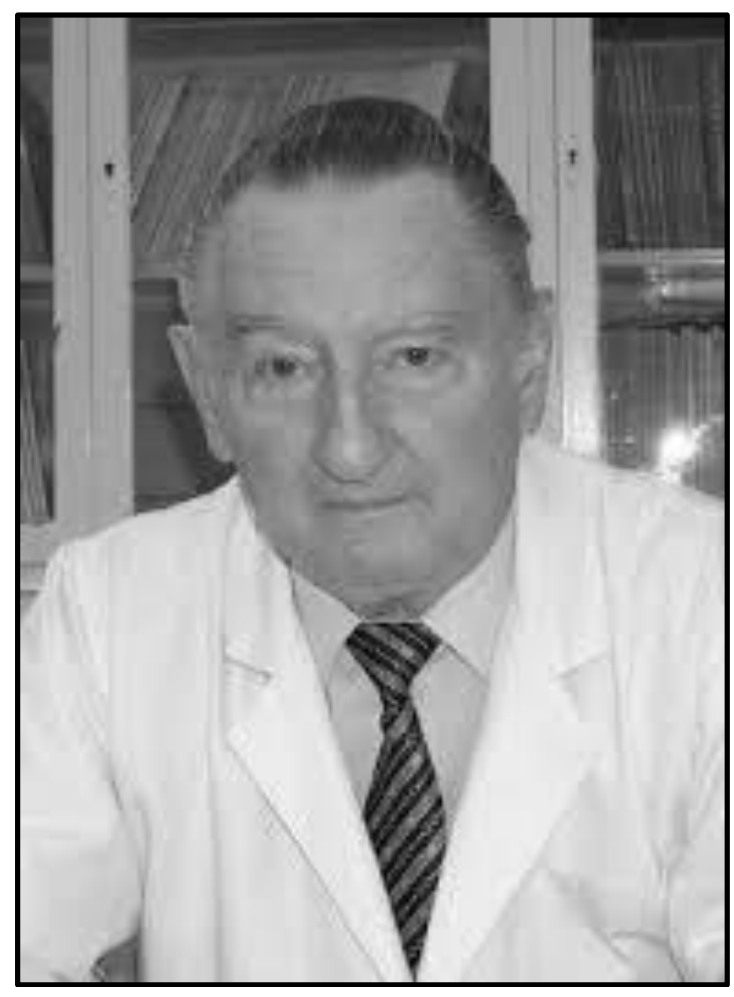

1. ábra: Prof. Dr. SeY OtTó (1936-2017)

Figure 1: Prof. Dr. OTTÓ SEY (1936-2017) 
SEY OTTÓ 1936. október 22-én, Kapuváron született SEY DEZSŐ pékmester és SZARADICS TERÉZIA hat gyermeke közül ötödikként a sorban. Általános iskolai tanulmányait a gartai, majd a II. számú, ma Pátzay Pál Általános Iskolában végezte. Társai közül kitűnt okosságával, szorgalmával, ezért Sopronba került a Berzsenyi Dániel Gimnáziumba (19511955), ahol 1955-ben érettségizett. Felsőfokú tanulmányait a Pécsi Állami Pedagógiai Főiskolán kezdte, amit kitüntetéssel végzett el, s lett 1959-ben biológia-földrajz szakos tanár (Okl. sz.: 435/1959.). Egyetemi tanulmányait a Szegedi majd József Attila Tudományegyetem Természettudományi Karán folytatta, ahol 1963-ban ugyancsak kitünő eredménnyel szerzett biológia-földrajz szakos középiskolai tanári képesítést (Okl. sz.: 131/1963.) (2. ábra). Szakdolgozatainak elkészítése során ismerte meg a Hanyt, a Hanságot, amelynek szeretete nem túlzás, szerelme - végigkísérte életét. Főiskolai szakdolgozatának (1958) címe: „Adatok a Hanság Vertebrata faunájához”, egyetemi dolgozatának (1963) pedig „A magyarországi pézsmapocok (Ondatra zibethica LiNK, 1795) belsöélösködö férgei” volt.

Tanári pályáját a Kapuvári Állami Gimnáziumban kezdte, tehát hazatért szülőföldjére. Ebben az időszakban - 1962-ben - kötötte össze életét NAGY GIZELLÁval, aki 55 éven keresztül megbonthatatlan szeretetben volt életének társa, jóban-rosszban biztos támasza. Főiskolai-egyetemi aktivitása, szakdolgozatainak téma-ismerete, de mindenekelőtt személyes kvalitása alapján hívta 1963-ban WÉBER MIHÁLY ${ }^{1}$ professzor, a tanszék alapító vezetője Pécsre, a Pedagógiai Főiskola Állattani Tanszékére tanársegédnek. Ekkor Pécsre költöztek, ahol 2001-ig, 28 évig éltek.

1963-ban elkezdődhetett és tág teret kapott az az egyetemi oktatói és kutató munka, ami értelmet adott életének, aminek során kiteljesíthette képességeit, tudását. Az Egri Tanárképző Főiskola, később a debreceni Agráregyetem tanára, EDELÉNYI BÉLA ${ }^{2}$ parazitológus hatására kezdett el parazitológiával foglalkozni, aminek első eredményeként fent említett szakdolgozatával Szegeden középiskolai tanári oklevelet szerzett. 1963-ban alapító tagja volt a Magyar Parazitológusok Társaságának.

1973-ban készítette el kandidátusi értekezését „A szarvasmarha és a juh hazai Paramphistomum fajainak rendszertani és a P. daubneyi DINNIK, 1962 fejlödésbiológiai vizsgálata" címmel, aminek megvédése után 1974-ben a biológiai tudományok kandidátusa lett (Okl. sz.: 6043) (3. ábra). Témavezetője KOBULEJ TIBOR ${ }^{3}$ professzor volt, az Állatorvostudományi Egyetemről.

Ekkor már élethosszig választott kutatási területe az Amphistoma-knak nevezett parazitacsoport lett, amelynek világhírü, meghatározó tudósává vált. Ugyanebben az évben adjunktussá, 1982-ben föiskolai docenssé nevezték ki, munkájának elismerését jelezte, hogy 1983-ban megkapta a Munka Érdemrend Ezüst Fokozata kitüntetést. Kutatásai egyre nagyobb

\footnotetext{
${ }^{1}$ WÉBER MiHÁLY (1916-2000) - a Pécsi Pedagógiai Főiskola Állattani Tanszékének alapítója (1950). Egyetemi tanulmányait Szegeden végezte, 1949-ben dr. UHERKOvich ÁKOs hívta Pécsre az állattani tárgyak oktatására. 1956-1957-ben a Föiskola igazgatója is volt. Az Állattani Tanszéket 1950-1976 között 26 évig vezette. Aktív élete során tanszéki és más főiskolák társtanszékein tanító kollégáival több olyan tankönyvet írtak, amelyek évtizedekig meghatározták a magyar tanárképzés biológiai oktatását. 2000-ben 84 éves korában hunyt el.

2 : EDELÉNYI BÉLA (1917-1988) - szegedi Állami Polgári Iskolai Tanárképző Főiskolán polgári iskolai tanári okl. (1940), tanítóképző intézeti tanári okl. (1942), a szegedi Ferenc József Tudományegyetemen bölcsészdoktori oklevelet szerzett (1943), a biológiai tudományok kandidátusa (1971). Az egri Pedagógiai Főiskola Földrajz Tanszékének adjunktusa (1956-1963). A Debreceni Agrártudományi Főiskola Növényállattani Tanszéke, ill. Állattan Tanszéke docense (1963-tól) és a Tanszék vezetője (1964-től) volt. A halak, kétéltüek és hüllők bélparazitáinak nemzetközileg is ismert kutatója volt.

${ }^{3}$ : KoBULEJ TiBOR (1921-1997) - állatorvos (1944), egyetemi tanár, az állatorvos-tudományok kandidátusa (1952), az Állatorvostudományi Egyetem Általános Állattani és Parazitológiai Tanszékének gyakornoka (19471948), adjunktusa (1948-1952), docense (1966-1968), professzora (1968-1982), a tanszék vezetöje (19651982), az Állatorvos-parazitológusok Világszövetségének alelnöke (1975-1978).
} 

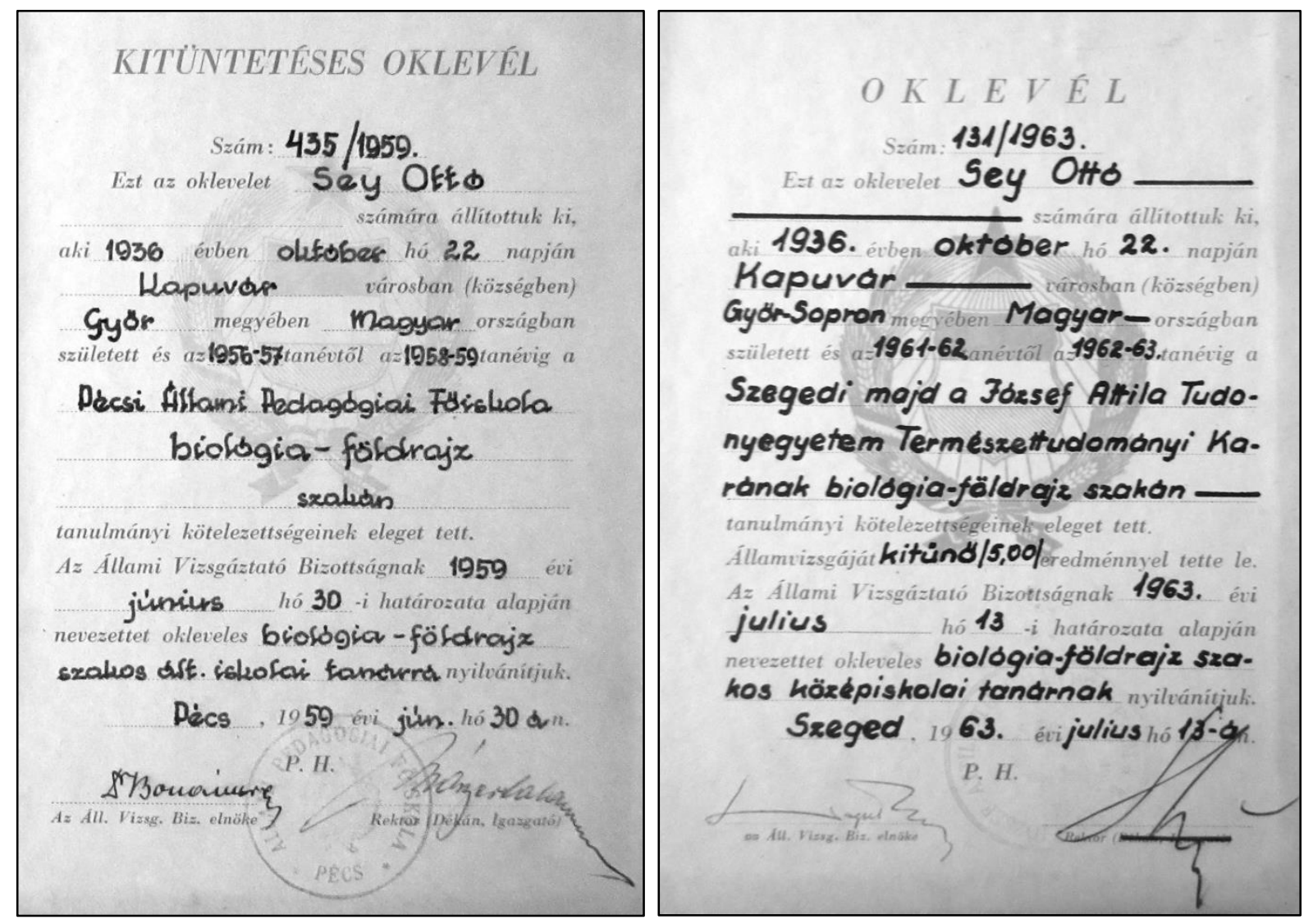

2. ábra: SEY OTTÓ főiskolai és egyetemi diplomája

Figure 2: Diplomas of OTTÓ SEY on BSc (left) and MSc (right) degree

földrajzi területet öleltek fel, a Balkán mellett Egyiptomban, Indiában, Vietnámban töltött el fél évet, vagy 3-3 hónapot.

1987-ben nyújtotta be a Magyar Tudományos Akadémiára „Az anfisztomumok filogenetikai mintázata - Phylogenetic relationships among amphistomes" c. akadémiai doktori értekezését, aminek sikeres megvédése után 1990-ben a biológiai tudomány akadémiai doktora (DSc) lett (Okl. sz.: 2733) (3. ábra).

1988-ban a Keszthelyi Agrártudományi Egyetem Keszthelyi Karának Állattani Tanszékéről nyugdíjba vonult KÖLÜS GÁBOR ${ }^{4}$ Professzor, aki utódjául hívta SEY OTTót, aki 1988. július 1. hatállyal egyetemi tanári kinevezést is kapott (4. ábra). 1988-tól az állattan tanszékvezető professzora lett Keszthelyen, az 1989-ben átalakított Pannon Agrártudományi Egyetem Georgikon Mezőgazdaságtudományi Karán.

1991-ben jelent meg az Egyesült Államokban nagy Amphistoma kézikönyve (Handbook of the Zoology of Amphistomes), amit a Pannon Agrártudományi Egyetem Pro Agricultura Pannoniae-díjjal ismert el (4. ábra).

E nagy nemzetközi elismerést hozó müvet aztán két további kötet követett e témában már idehaza. Közben 1991 és 1993 között szerkesztő-bizottsági tagja volt a Parasitologia Hungarica periodikának is.

\footnotetext{
4 : KÖLÜS GÁBOR (1922-2008) - agrármérnök (1946), 1950-től a Gödöllői Agrártudományi Egyetem Állattani Tanszékének adjunktusa (1950-1957), 1957-ben visszatér Keszthelyre, 1958-tól tanszékvezető docens volt a Növénytan-Állattan Tanszéken. A mg. tudományok kandidátusa (1971), egyetemi tanár, tanszékvezető nyugdíjazásáig (1975-1988).
} 

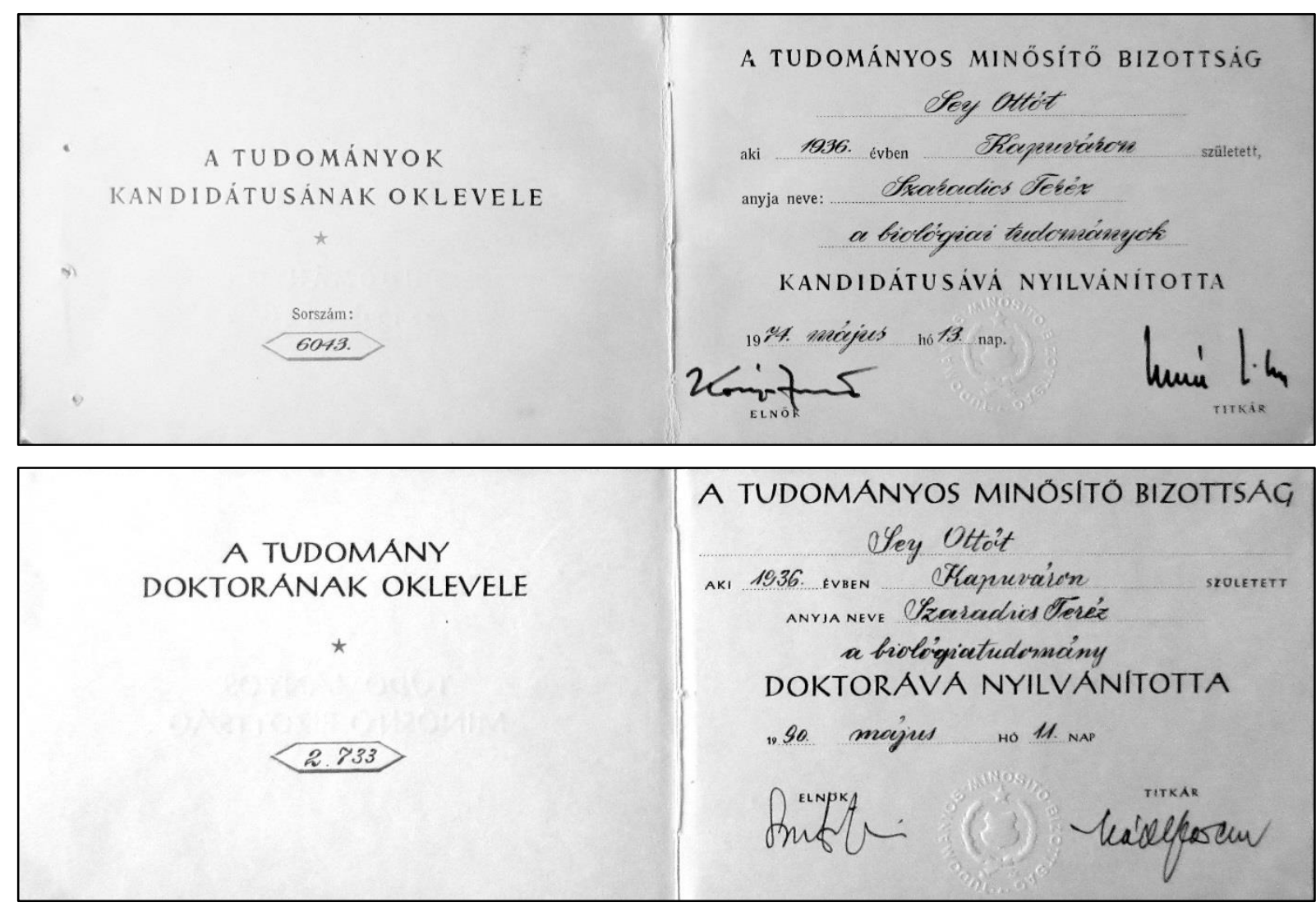

3. ábra: Sey Ottó kandidátusi és akadémiai doktori oklevele

Figure 3: Certificate of Ottó Sey on PhD (over) and DSc (below) degree

Négy év keszthelyi tartózkodás után megpályázta és elnyerte a Kuvaiti Egyetem Biológiai Tanszékének professzori pozícióját, amit 1992-1999 között töltött be. A különleges arab világba is jól beilleszkedett, munkatársai elismerték, kedvelték. Kuvaiti kutatásai az Arab-öböl térségére, illetve Thaiföldre koncentráltak - változatlanul a parazitológia területén. Szerdánként a halpiacon kezdte napját, ahol boncolt, parazitákat gyüjtött. Sokat publikált e témakörben. Közben 1996-ban - a BoKROS-csomag folyományaként - Keszthelyen megszüntették professzori munkahelyét, nyugdíjba küldték, amit még a távolból is nehezen viselt. Ennek volt köszönhető, hogy amikor 1999-ben hazatért Kuvaitból, akkor nyugdíjasként nem Keszthelyre tért vissza, hanem ismét - két évig - a Pécsi Egyetemen volt óraadó. Mert az oktatást, hallgatóit szerette, nehezen tudott nélküle, nélkülük élni.

Tagja volt a Magyar Tudományos Akadémia Zoológiai Bizottságának, Agrártudományi Szakbizottságának, a Diverzitásbiológiai Bizottságnak és a Veszprémi Területi Bizottságnak (VEAB).

2001-től aztán megváltozott élete, életük, amikor áttelepültek Mosonmagyaróvárra, később pedig Sopronba. Még korábbi anyagait dolgozta fel, cikkeket publikált, könyveket írt: 2001-ben az Amphistomes of the World: A check-list of amphistomes of vertebrates, 2005-ben a Keys to the identification of the taxa of the Amphistomes (Trematoda, Amphistomatida), 2009ben A Fertö-Hanság Nemzeti Park gerinces állatainak élösködői c. mü került ki kezei közül.

Romló egészégi állapota már egyre kevésbé engedte meg a terepi munkát. Ezt a gyengeséget nehezen élte meg, s csak szerető felesége biztatása, támogatása tudta kiemelni az apátiából. Pedig mennyire vágyott a Hany után, mennyire hiányoztak neki a gyüjtő utak. Azért vadászott, azért horgászott, hogy a terítékre hozott állatokat, megfogott halakat megvizsgálhassa. 

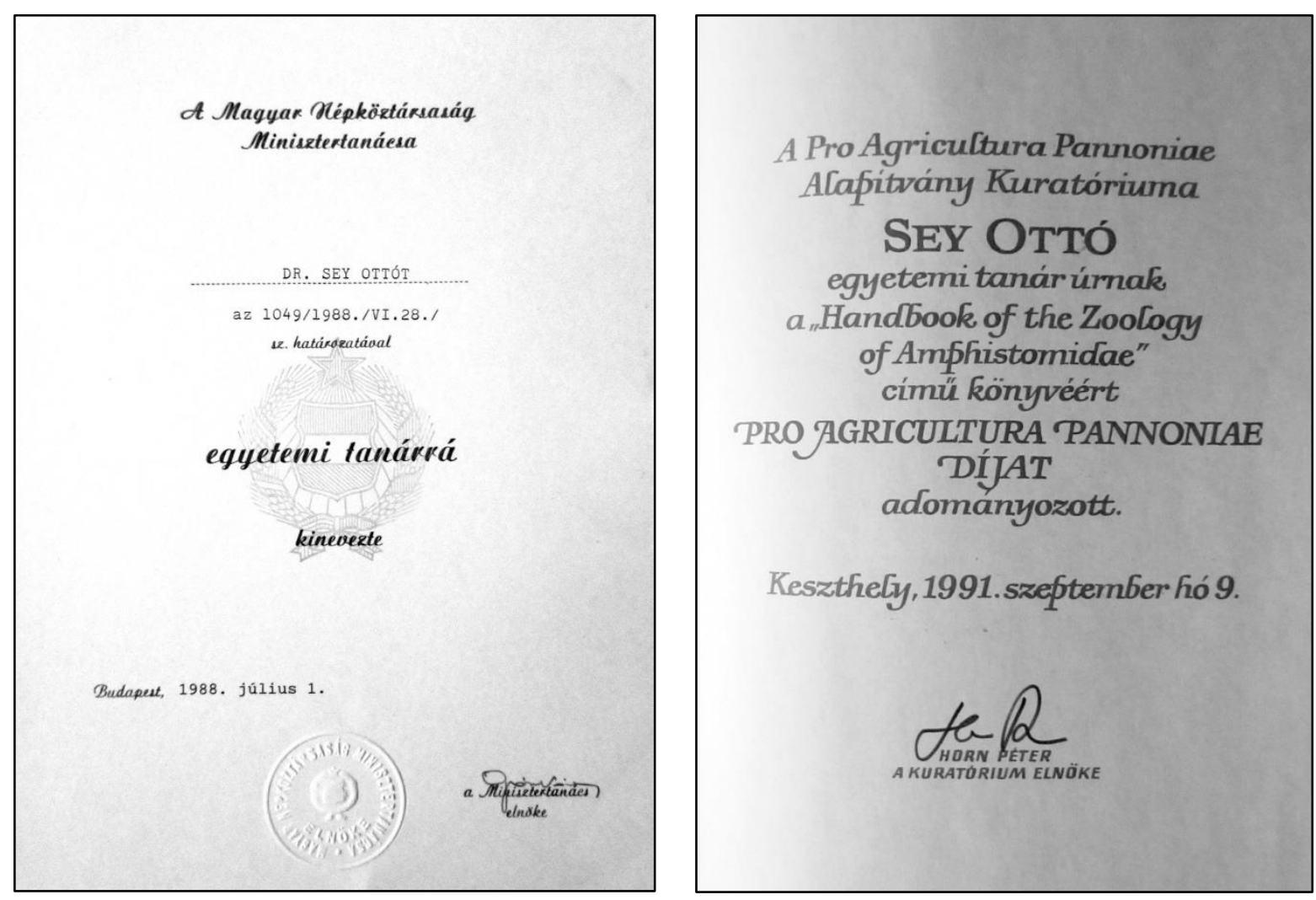

\section{4. ábra: Sey OtTó professzori kinevezése és Pro Agricultura Pannoniae-díja}

Figure 4: Professor Appointment document (left) and Pro Agricultura Pannoniae Prize (right) of OTTÓ SEY

Tanári munkája elején a preparálásban is jeleskedett, a Kapuvári Gimnázium biológia szertárát saját gyüjtéseivel, preparátumaival gazdagította. Rajongott hivatásáért, valóban feltette életét az oktatásra és a tudományos kutatásra.

Élete leszálló szakaszában rovargyüjteményét a győri Xantus János Múzeumra, világhírü Amphistoma kollekcióját pedig a Magyar Természettudományi Múzeumra hagyományozta, ami a Múzeum Parazitológiai Gyüjteményének elkülönített egységét képezi.

Tudósként, kutatóként kétséget kizárólag maradandót alkotott, - tudományos teljesítménye nemzedékek számára jelent majd igazodási pontot (lásd publikációs jegyzékét).

A méltánylandó tudós alkat mellett SEY OTTÓ professzor kiváló EMBER is volt. Kapcsolata mindenkori munkatársaival felhőtlen volt, akkor is, amikor vezetői székben ült, akkor is, amikor még csak egy volt közülük. Barátaihoz hüséggel ragaszkodott, szerette a társaságot, itthon és külhonban egyaránt. Úgy lett a társaság központja, hogy nem volt harsány, de jókedvü, okos gondolataival, egyedi humorával könnyen megnyerte barátainak szívét.

Életfilozófiáját legjobban azzal a BERZSENYI DÁNIEL idézettel - hiszen rajongott az irodalomért is - lehet jellemezni, amit a niklai remete írt ViTKOVICs MiHÁLYnak, Ö pedig kuvaiti búcsúztatásakor mondott el magyar kolóniabeli barátainak:

„,Rendeltetésünk nem magányos élet,

Sörök komolyság és elmélkedés,

Hanem barátság és társalkodás.

S nem a világi jókat megtagadni,

De józan ésszel vélek élni tudni,

A bölcsességnek titka és jele." 
Igen, SEY OTTó professzorra egyként volt jellemző a komolyság és elmélkedés, a barátság és társalkodás, s nem tagadta meg a világi jókat sem. Bölcs emberként, józan ésszel élt minden földi adománnyal.

2017. Karácsonyán SEY OTTÓ professzor visszaadta lelkét teremtőjének, 2018. január 4-én kísértük utolsó útjára a Kapuvári Szent Kereszt Temetőben. A volt pécsi kollégák és tanítványok nevében Dr. MOLNÁR LÁSZLÓ tanszékvezető egyetemi docens, a család, a barátok és pályatársak nevében e sorok szerzője búcsúztatta az elhunytat. Engedtessék meg néhány személyes sor is e helyütt a búcsúbeszédből:

„Elment - de nekem mégsem a gyötrelmektől felszabadító elmúlás, hanem a mindig mosolygós, okos, céltudatos, sikeres, életerős földim, SEY OTTÓ Professzor délceg alakja sejlik fel a legbensőbb emlékeimből - 60 éve ismerem, fájdalom 60 évig ismertem Öt.

Elment, mert mindnyájunknak ez a sorsa, de itt is marad velünk, mert szívünk, lelkünk nem engedi el Öt, mert bennünk, általunk, tovább él, tovább kell, hogy éljen.

Mert a végső fájdalmakat megelőzően SEY OTTÓ olyan szép és teljes életet élt, amelynek eredményeként sokaknak befészkelte magát szívébe. Ezért is írhattam, hogy Ő bennünk, általunk tovább él. Keveseknek adatik meg ez!

A fent leírtak alapján különösen nehéz elfogadni, tudomásul venni, hogy SEY OTTÓ professzor, szeretett hozzátartozónk, barátunk, mesterünk e földi létből elköltözött. Nem hallgathatjuk többé okos gondolatait, baráti szavait, de tudományos munkáiban velünk lesz örökre.

A szerető férj, a jó rokon elvesztése az egyik legnagyobb csapás, ami érző embert érhet. Nehéz lesz megérteni és elfogadni, hogy már nincs velünk, nincs kivel megosztani örömünket, gondjainkat, vagy bánatunkat. Nincs az óvó, simogató, támogató kéz. De megmaradnak az együtt megélt évtizedek, a feledhetetlen órák, percek, a kitörölhetetlen emlékek. Megmarad a mosoly, a biztató vagy hálás szemvillanás, a lélek és a szeretet, amely - örökké velünk marad."

\section{Sey OtTó Publikációs jegyzéke}

\section{4}

1. SEY, O. (1964): Adatok a Hanság gerinces állatainak ismeretéhez. Arrabona 6: 347-384.

2. SEY, O. (1964): Tanulmányok a magyarországi parazita féregfaunáról I. Pécsi Tanárképzö Föiskola Tudományos Közleményei (PTFTK): 413-437.

3. SEY, O. (1964): A pézsmapocok (Ondatra zibethica) akklimatizációjának hatása belsőélősködő férgeinek összetételére. Szegedi Tanárképzö Főiskola Tudományos Közleményei (SZTFTK): $143-150$.

\section{5}

4. SEY, O. (1965): Tanulmányok a magyarországi parazita féregfaunáról II. Pécsi Tanárképző Föiskola Tudományos Közleményei (PTFTK): 179-199.

5. SEY, O. (1965): A pézsmapocok (Ondatra zibethica L. 1776) magyarországi belső élősködő férgei I. Vertebrata Hungarica 7: 158-175.

\section{6}

6. SEY, O. (1966): Contribution to the knowledge of the internal parasites of muskrat (Ondatra zibethica L. 1776) living along the river Tisa. Tiscia 2: 89-95.

7. SEY, O. (1966): Adatok a szárcsa (Fulica atra) parazita féregfaunájához. Állattani Közlemények 53: $123-130$. 
8. SEY, O. (1966): Adatok vadon élő madaraink parazita féregfaunájához I. Pécsi Tanárképző Föiskola Tudományos Közleményei (PTFTK): 53-71.

\section{7}

9. SEY, O. (1967): Modifications of the American muskrat's (Ondatra zibethica L.) parasitic fauna due to acclimatization. Acta Zool. Acad. Sci. Hung. 13: 409-416.

10. SEY, O. (1967): Szívóférgek a Budapesti Állatkertben tartott adriai halakból. Állattani Közlemények 14: 135-138.

11. SEY, O. (1967): Adatok vadon élő madaraink parazita féregfaunájához II. Pécsi Tanárképző Föiskola Tudományos Közleményei (PTFTK): 47-65.

\section{8}

12. SEY, O. (1968): Parasitic helminths occurring in Adriatic fishes I. Acta Adriatica 13: 1-15.

13. SEY, O. (1968): Trematodes from birds living along the river Tisa. Tiscia 4: 59-68.

14. SEY, O. (1968): Cestodes from birds living along the river Tisa. Tiscia 4: 69-78.

15. SEY, O. (1968): Adatok a Bakony gerinces állatainak parazita féregfaunájához I. Veszprém Megyei Múzeumok Közleményei (VMMK) 7: 315-325.

\section{9}

16. SEY, O. (1969): Galandférgek vadászati-halászati szempontból jelentős madarakból. Állattani Közlemények 56: 121-129.

17. SEY, O. (1969): The influence of size and duration of infections changes in the sex ratio of Nippostongylus brasiliensis population in rats. Parasitologia Hungarica 2: 45-54.

\section{0}

18. SEY, O. (1970): Parasitic helminths occurring in Adriatic fishes II. Acta Adriatica 13: 1-16.

19. SEY, O. (1970): Parasitic helminths occurring in Adriatic fishes III. Acta Adriatica 13: 1-16.

20. SEY, O. (1970): Collarinema triglae gen. et sp. nov. (Nematoda: Rhabdochonidae) from the red gurnerd (Trigla lyra, L.) in the Adriatic, Yugoslavia. Acta Zool. Acad. Sci. Hung. 16: 209-214.

\section{1}

21. SEY, O. (1971): Gametogenesis in Paramphistomum microbothrium Fischoeder, 1901. Acta Vet. Acad. Sci. Hung. 21: 93-106.

22. Sey, O., Mikes, M., Soti, J. \& Dimitrijevic, S. (1971): Trematodes of birds occurred in Vojvodina. Zbor. rad. pri.-matk. fak. Univ. Novi Sad 1: 193-210.

1972

23. SEY, O. (1972): Investigation on the eggs, the process of embryo-formation and of the structure of miracidium of Paramphistomum daubneyi Dinnik, 1962. Parasit. Hung. 5: 17-38.

24. Soti, J., SEy, O. \& MikeS, M. (1972): Trematodák és Cestodák vajdasági madarakból. Pécsi Tanárképzö Főiskola Tudományos Közleményei (PTFTK) 16: 13-24.

25. Sey, O., Csontos, F., Jeckel, K. \& Deszecsár, M. (1972): A higiénés viszonyok és az óvodás közösségek parazitás fertőzöttségének alakulása. X. Biol. Vándorgy., Szeged, p. 48.

1973

26. SEY, O. (1973): A Paramphistomum daubneyi Dinnik, 1962 petéinek kikelési mechanizmusa. Állattani Közlemények 60: 95-101. 
27. SEY, O. (1973): Histological characterization of the pharynx, genital atrium and the acetabulum of Nematophila grande (DIESING, 1839) (Trematoda, Paramphistomata). Parasit. Hung. 6: 6367.

28. SEY, O. (1973): Adatok a Bakony gerinces állatainak parazita féregfaunájához II. Veszprém Megyei Múzeumok Közleményei (VMMK) 12: 231-240.

29. SEY, O. (1973): Adatok a Bakony gerinces állatainak parazita féregfaunájához III. Veszprém Megyei Múzeumok Közleményei (VMMK) 12: 241-251.

30. CsOntos, F., SEY, O. \& STEINER, J. (1973): A szennyvíz okozta talajfertőzés következtében létrejött geohelminth „endémia” gyermekotthoni kollektívában. Népegészségügy 14: 61.

\section{4}

31. SEY, O. (1974): On the validity of Paramphistomum microbothrioides PRICE et MCINTOSH, 1944. Acta Zool. Acad. Sci. Hung. 20: 183-186.

32. SeY, O. (1974): On the species of Paramphistomum of cattle and sheep in Hungary. Acta Vet. Acad. Sci. Hung. 24: 19-37.

33. TÓTH, E., CsOnTOS, F., SEy, O. \& BÉKEFI, I. (1974): A Trichomonas vaginalis és a harkányi gyógyfürdö. Magyar Nöorvosok Lapja 37: 367-369.

1975

34. SEY, O. (1975): Histological examination on the muscular organs of some amphistomes (Trematoda: Paramphistomata). Parasit. Hung. 8: 55-59.

35. SEY, O. (1975): Some remarks on the European species of Paramphistomum having microbothrium type of genital opening. Proc. $2^{\text {nd }}$. Europ. Multicol. Parasit., Trogir, p 76.

36. Sey, O. \& Albel-Rahman, M.S. (1975): Studies on Paramphistomum species of cattle and sheep in Egypt. Assuit Vet. Med. Journ. 2: 145-149.

37. Mikes, M., Soti, J., SEy, O. \& DimitriJevic, S. (1975): Survey of the Trematodes of the fisheating birds in Vojvodina. Archiv. Biol. Nauka 26: 55-59.

38. Soti, J., MiKeS, M. \& SEY, O. (1975): Some trematodes of fish-eating birds of Skadar lake (Yugoslavia). Proc. $2^{\text {nd }}$. Europ. Multicol. Parasit., Trogir, pp: 275-280.

39. MiKes, M., Soti, J. \& SEY, O. (1975): Remarks on some plathelminthes and acanthocephala from Pica pica and Corvus cornix in Yugoslavia. Proc. $2^{\text {nd }}$. Europ. Multicol. Parasit. Trogir, pp: 337-341.

1976

40. SEY, O. (1976): Studies on the stomach flukes of buffalo in Egypt (Trematoda: Paramphistomata). Folia Parasit. (Praha) 23: 237-242.

41. SEY, O. \& SAYED, R. I. (1976): Examination of the pre-parasitic stages of two fish amphistomes. Acta Zool. Acad. Sci. Hung. 22: 165-171.

42. Tóth, E., CsOntos, F., SEY, O. \& BÉKEFI, I. (1976): Trichomonas vaginalis und das Heilbad von Harkány. Z. angew. Bader-und Klimaheik. 23: 49-50.

43. SEY, O. \& VISNYAKOV, Y. (1976): Examination of paramphistomid species of Bulgarian domestic ruminants. Parasit. Hung. 9: 25-29.

1977

44. SEY, O. (1977): Examination of helminth parasites of marine turtles caught along the Egyptian coast. Acta zool. Acad. Sci. Hung. 23: 387-394.

45. SEY, O. (1977): Examination of amphistomes (Trematoda: Paramphistomata) parasitizing in Egyptian ruminants. Parasit. Hung. 10: 47-50.

46. SEY, O. (1977): A fejlődési ciklus szolgáltatta információk, mint a Paramphistomum daubneyi európai előfordulásának bizonyítékai. In: REDL, P. (szekr.): A Kotlán Sándor tudományos 
emlékülés elöadásainak összefoglalói, Budapest, 1977. június 9-10. Állatorvos-tudományi Egyetem, Budapest. pp: 23.

47. SEY, O. \& ARRU, E. (1977): A revision of species of Paramphistomum Fischoeder, 1901 occurring in Sardinian domestic ruminants. Riv. Parassit. 38: 295-301.

\section{8}

48. SEY, O. (1978): Examination of rumen flukes (Trematoda: Paramphistomata) of cattle in Rumania. Parasit. Hung. 11: 23-25.

49. SEY, O. \& PALMiERI, J. R. (1978): Histo-morphological structure of the muscular organs of Stunkardia minuta PALMIERI et SUllivan, 1966 (Trematoda: Paramphistomata). Parasit. Hung. 11: 27-29.

50. SEY, O. (1979): Life-cycle and geographical distribution of Paramphistomum daubneyi DINNIK, 1962 (Trematoda: Paramphistomata). Acta Vet. Acad. Sci. Hung. 27: 115-130.

51. SEY, O. (1979): Examination of validity and systematic position of some paramphistomids of Indian ruminants. Parasit. Hung. 12: 31-36.

52. SEY, O. \& GRABER, M. (1979): Examination of amphistomes (Trematoda: Paramphistomata) of some African mammals. Rev. Elev. Méd. vét. Pays trop. 32: 161-167.

53. SEY, O. \& GRABER, M. (1979): Cotylophoron macrosphinctris sp. n. (Trematoda: Paramphistomata) from the African buffalo, Bubalus (Syncerus) caffer Sparrman. Annl. Parasit. 54: 279-302.

54. SEY, O. \& MAJER, J. (1979): Állatrendszertani gyakorlatok. Tanárképző Főiskolák egységes jegyzete. Tankönyvkiadó, Budapest. 320 p.

1980

55. SEY, O. (1980): Re-examination of an amphistome (Trematoda) collection deposited in the Geneva Museum with a description of Orthocoelium saccocoelium sp. n. Revue suisse Zool. 87: 431-437.

56. SEY, O. (1980): Amphistome parasites of the dugong and revision of the subfamily Solenorchiinae (Trematoda: Paramphistomatidae). Acta Zool. Acad. Sci. Hung. 26: 223-228.

57. SEY, O. (1980): Revision of the amphistomes of European ruminants. Parasit. Hung. 13: 13-25.

58. SEY, O. \& GRABER, M. (1980): Nilocotyle duplicisphinctris sp. n. (Trematoda: Paramphistomidae) from Hippopotamus amphibius. J. Helminthol. 54: 123-127.

\section{1}

59. SEY, O. (1981): Ecological aspects of mass production of metacercariae of Paramphistomum daubneyi. $9^{\text {th }}$ Int. Conf. of W. A. V. P. Bp. Abstract p: 166.

60. Albaret, J.-L., Bayssade-Dufour, Ch., Diaw, O. T., Vassiliades, G., Sey, O. \& Gruner, L. (1981): Disposition des organites argyrophiles superficiels du miracidium et de la cercariae de Paramphistomum phillerouxi Dinnik, 1961 (Trematoda: Paramphistomidae). Annl. Parasit. 56: $147-154$.

\section{2}

61. SEY, O. (1982): Ecology of larval stages of Paramphistomum daubneyi Dinnik, 1962 (Trematoda, Paramphistomidae). Abstr. Rep. IVth. Inter. Symp. Helminth. Inst. Kosice, Chechoslovakia, p: 2.

62. SEY, O. (1982): Revision of the genus Cotylophoron Stiles et Goldberger, 1910 (Trematoda, Paramphistomidae). Helminthologia 19: 11-24.

63. SEY, O. (1982): The morphology, life-cycle and geographical distribution of Paramphistomum 
cervi (ZEDER, 1790) (Trematoda: Paramphistomata). Miscnea Zool. Hung. 1: 11-24.

64. SEY, O. \& Eslami, A. (1982): Review of amphistomes (Trematoda, Paramphistomata) of Iranian domestic ruminants. Parasit. Hung. 14: 61-65.

\section{3}

65. SEY, O. (1983): Revision of the family Gastrothylacidae Stiles et Goldberger, 1910 (Trematoda, Paramphistomata). Acta Zool. 29: 223-252.

66. SEY, O. (1983): Reconstruction of the systematics of the family Diplodiscidae SKRJABIN, 1949 (Trematoda, Paramphistomata). Parasit. Hung. 16: 63-89.

67. SeY, O. \& SzÁZADOS, I. (1983): Bendőmételyek Paramphistomum daubneyi DinNIK, 1962 a szarvasmarha gégéjében. Parasit. Hung. 16: 91-92.

68. SEY, O. \& BÖRÖCZKY, K. (1983): Bendőmételykór vizsgálata a gemenci gímszarvasokban és özekben. Nimród Fórum 1983. október: 22-24.

\section{4}

69. SEY, O. (1984): Description of Watsonius papillatus sp. $\mathrm{n}$. and the revision of the subfamily Watsoniinae Nasmark, 1937 (Trematoda, Paramphistomata). Acta Zool. 30: 493-510.

70. SEY, O. (1984): Scanning electron microscopic examination of the tegumental surface of some amphistromes (Trematoda, Amphistomida). Parasit. Hung. 17: 45-49.

71. Samnaliev, P., SEY, O. \& Dimitrov, V. (1984): Nomenclature of the argentofile structures of miracidia. Argentofile structure of miracidium Paramphistomum ichikawai FUKUI, 1922. In: The Abstracts of Fourth European Multicolloquium on Parasitology (E.M.O.P. IV.) Izmir. pp: 143-144.

72. SEY, O. \& KASSAI, T. (1984): Néhány anthelmintikum juhok vékonybél-paramphistomosisa elleni hatékonyságának vizsgálata. MTA-MÉM Akadémiai Beszálmoló (Parazitológia Halkórtan) 11: 17.

\section{5}

73. SEY, O. (1985): Review of pouched amphistomes of Vietnamese ruminants, with a description of Carmyerius bulbosus sp. n. (Trematoda, Amphistomida). Misc. Zool. Hung. 3: 31-35.

74. SEY, O. (1985): Amphistomes of Vietnamese vertebrates (Trematoda, Amphistomida). Parasit. Hung. 18: 17-24.

75. SEY, O. (1985): A kérődzők paramphistomosisának tanulmányozása és a racionális védekezés kimunkálása, In: KoRÁNYI, J. (összeáll.): 1982-85. évi Állami Megbízási Kutatások 2. Természettudományi Müszaki tudományok, Tudszervezési és Informatikai Intézet, Budapest. pp. 287-289.

76. Le NGUYen Thi \& SEY, O. (1985): Infectivity of metacercariae of Fasciolopsis buski (Lankester, 1857) and their development in definitive host. Parasit. Hung. 18: 11-15.

77. Moravec, F. \& SEY, O. (1985): Some nematode parasites of frogs (Rana spp.) from North Vietnam. Parasit. Hung. 18: 63-77.

78. SEY, O. (1985): A pézsmapocok karrierje. Élet és Tudomány 40 (48): 1518-1519.

\section{6}

79. SEY, O. (1986): Description some new taxa of amphistomes (Trematoda, Amphistomida) from Vietnamese freshwater fishes. Acta Zool. 32: 161-168.

80. BORAY, J.C. \& SEY, O. (1986): The importance of mollusc-trematode relationship in the distribution and epidemiology of fascioliasis and paramphistomiasis. Proc. $8^{\text {th }}$ Inter. Mal. Cong. Budapest, 1983. pp: 39-42.

81. SEY, O. \& MorAVEC, F. (1986): An interesting case of hyperparasitism of the nematode Spiranura babei HA KY, 1971 (Nematoda: Kathlaniidae). Helminthologia 23: 173-177. 
82. Moravec, F. \& Sey, O. (1986): Three new nematode species from Phrynomantis spp. (Amphibia: Microhylidae) from Papua New Guinea. Folia Parasit. 33: 343-351.

\section{7}

83. Raina, M.K., SEY, O. \& Khan, M. D. (1987): Paramphistomes (Trematoda: Amphistomida) of domestic ruminants in Kashmir, India. Miscnea Zool. Hung. 4: 5-12.

84. SEY, O. (1987): Typifying and classifying of the muscular organs of amphistomes (Trematoda: Amphistomida). Parazit. Hung. 20: 45-63.

\section{8}

85. Moravec, F. \& SEY, O. (1988): Nematodes of freshwater fishes from North Vietnam. Part 1. Camallanoidea and Habronematoidea. Vest. cs. Spolec. Zool. 52: 128-148.

86. SEY, O. (1988): Scope of and proposal for systematics of the Amphistomes (LUHE, 1909), ODENING, 1974 (Trematoda). Parasit. Hung. 21: 17-30

87. MoraVeC, F. \& SEY, O. (1988): Nematodes of freshwater fishes from North Vietnam. Part 2. Thelazoidea, Physalopteroidea and Gnathostomatoidea. Vest. cs. Spolec. Zool. 52: 176-191.

88. MoraVeC, F. \& SEY, O. (1988): Nematodes of freshwater fishes from North Vietnam. Part 3. Cosmocercoidea, Seuratoidea, Atractoidea, Heterakoidea and Ascaridoidea, Vest. cs. Spolec. Zool. 52: 250-265.

89. MoraVeC, F. \& SEY, O. (1988): Some trematodes of freshwater fishes from North Vietnam, with a list of recorded endohelminths by fish hosts. Folia Parazit. 36: 243-262.

90. SEY, O. \& VARGA, J. (1988): Evolúció. Tanárképző Főiskolák egységes jegyzete. Tankönyvkiadó, Budapest. 226 p.

\section{9}

91. SEY, O. (1989): Laboratory model for studying experimental fasciolopsiosis. Miscnea Zool. Hung. 5: 9-11.

92. MoraVec, F. \& SEY, O. (1989): Acanthocephalans of freshwater fishes from North Vietnam. Vest. cs. Spolec. Zool. 53: 89-106.

93. SEY, O. (1989): A review of chemotherapy of paramphistomosis of domestic ruminants in Europe. Parasit. Hung. 22: 51-55.

94. MoraVeC, F. \& SEY, O. (1989): Some amphibian trematodes from Vietnem and Papua New Guinea. Vest. cs. Spolec. Zool. 53: 265-279.

95. Dimitrov, V., Samnaliev, P. \& SeY, O. (1989): Nomenclature for the description of agrentiphilic stuctures of miracidia. Khelmintol. 27: 10-14.

\section{0}

96. SEY, O. (1990): Recovery of Skrjabinoplagiorchis ondatrae (ANDREJKO, 1965) (Trematoda: Plagiorchiidae) and Troglotrema srebarni GENOV, 1964 (Trematoda: Troglotrematidae) from the muskrat in Hungary. Parasit. Hung. 23: 33-38.

97. MoraVeC, F. \& SEY, O. (1990): Some nematode parasites of frogs from Papua New Guinea and Australia. Acta Soc. Zool. Bohemoslov. 54: 268-286.

98. Dimitrov, V., SAMnaliev, P. \& SEY, O. (1990): Argentophilic stucture on the miracidium of Paramphistomum ichikawai FUKUI, 1922 (Trematoda, Paramphistomidae). Khelmintol. 28: 3742.

\section{1}

99. SEY, O. (1991): Examination of the paramphistomosis in Hungarian games. In: CSÁNYI, S. \& ERnhAFT, J. (Ed.): Transactions of the $X X^{\text {th }}$ Congress of the International Union of Game Biologist, Gödöllö, 21-26. Aug. 1991, Hungary. Part 2. pp. 762. 
100. SEY, O. (1991): Examination of ecological factors regulating interactions in a host-parasite system. In LÁNG I. (szerk.): Advances in Biological research in Hungary, 1986-1990, Ecology. pp. 26-28.

101. Sey, O. (1991): The amphistomes of Hungarian Vertebrates. Parasit. Hung. 24: 59-68.

102. SEY. O. \& GRABER, M. (1991): Description of Ogmocotyle africanum sp. n. (Trematoda, Notocotylidae) from the hippopotamus and review of the Ogmocotyle SKRJABIN et. SCHULZ, 1933. Acta Zool. Hung. 37: 257-261.

103. SEY, O. (1991): Handbook of the Zoology of Amphistomes. CRC Press. Inc. Boca Raton, U.S.A. $480 \mathrm{p}$.

\section{2}

104. SEY, O. \& EÖRY, K. (1992): Helminth parasites of amphibians of Lake Balaton area. Miscnea Zool. Hung. 7: 5-8.

105. MurAi, É., MÉSZÁROS, F. \& SEY, O. (1992): On parasitic helminths of mammals living in the environs of Lake Balaton. I. Parasit. Hung. 25: 23-36.

\section{3}

106. MATSKÁSI, I. \& SEY, O. (1993): Contribution to the Monogenea fauna of the fishes of Lake Balaton. Parasit. Hung. 26: 11-14.

\section{4}

107. SEY, O. \& ESLAMI, A. (1994): Review of amphistomes (Trematoda, Paramphistomata) of Iranian domestic ruminants. Arch. Fac. Vet. Med, Teheran Univ. 6: 271-278.

108. SEY, O. \& Prasitirat, P. (1994): Amphistomes (Trematoda, Amphistomida) of cattle and buffalo in Thailand. Miscnea Zool. Hung. 9: 11-17.

\section{5}

109. SEY, O. (1995): Description of Bianium arabicum sp. n. (Trematoda, Lepocreadiidae) from the puffersfish, Lagocephalus lunaris (BLOCH et SCHNEIDER, 1801) in Kuwait and a review of the genus Bianium STUNKARD, 1930. Parasit. Hung. 28: 3-20.

1996

110. Thatcher, V.E., SeY, O. \& JÉGU, M. (1996): New amphistome (Trematoda) Genera and species from Amazonian serrasalmid fishes, Myleus (Myloplus). Acta Zool. Hung. 42: 261-270.

111. Ho, J. S. \& SEY, O. (1996): Parasitic copepoda of marine fishes from Kuwait: a preliminery report. Kuwait J. Sci. Eng. 23: 61-69.

112. AmIN, O. M. \& SEY, O. (1996): Acanthocephala from Arabian Gulf Fishes off Kuwait, with Descriptions of Neoechinorhynchus dimorphospinus sp. n. (Neoechinorhynchidae), Tegorhynchus holospinosus sp. n. (Illiosentidae), Micracanthorhynchina kuwaitensis sp. $\mathrm{n}$. (Rhadinorhynchidae), and Key to Species of the Genus Micracanthorhynchina. J. Helminthol. Soc. Wash. 63: 201-210.

113. SEY, O. (1996): Copulating flukes demonstrated on Kuwaiti fish trematodes. Parassitologia 38: 95.

1997

114. Sey, O., Prasitirat, P., Romratanapun, S. \& Mohkaew, K. (1997): Morphological studies and identification of rumen flukes of cattle in Thailand. Riv. Parassit. 14: 247-256.

115. SEY, O. \& NAHHAS, F. M. (1997): Digenetic trematodes of marine fishes from the Kuwaiti coast of the Arabian Gulf: Family Monorchiidae ODHNER, 1911. J. Helminthol. Soc. Wash. 64: 1-8. 
116. PetTer, A. J. \& SEY, O. (1997): Nematode parasite of marine fishes from Kuwait with a description of Cucullanus trachinoti n.sp. from Trachinotus blochi. Zoosystema 19: 35-59.

117. Ho, J. S. \& SEY, O. (1997): New species of Berea (Copepoda, Chondracanthidae) parasitic on a flouder from Kuwait. Pakistan Journal of Marine Sciences 6: 53-57.

\section{8}

118. Sey, O. \& Petter, A. J. (1998): Prevalence of ascaridoid larvae in Kuwait food fishes. Kuwait J. Sci \& Eng. 25: 435-442.

119. Amin, O. M., Wongsawad, C., Marayong, T., Saehoong, P., Suwattanacoupt, S. \& Sey, O. (1998): Sphaerechinorhynchus macropisthospinus sp. n. (Acanthocephala: Plagiorhynchidae) from Lizards, Frogs, and Fish in Thailand. J. Helminthol. Soc. Wash. 65: 174-178.

120. Sey, O., AL-Ghaith, L. \& NAhHAS, F. M. (1998): Scanning electron microscopy study of a copulating Monorchiid (Trematoda: Digenea). J. Helminthol. Soc. Wash. 65: 243-245.

121. NAHHAS, F. M., SEY, O., Hishimoto, R. (1998): Digenetic trematodes of marine fishes from the Kuwaiti Coast of the Arabian Gulf: Families Pleorchiidae, Fellodistomidae, and Cryptogonimidae, with a Description of two new species, Neoparacryptogonimus sphericus and Paracryptogonimus ramadani. J. Helminthol. Soc. Wash. 65: 129-140.

122. NAHHAS, F. M. \& SEY, O. (1998): Chauhanotrema spiniacetabulum sp. n. (Digenea: Waretrematidae) from Hemiramphus marginatus (Forsskal) (Hermiramphidae) from the Kuwatit Coast of the Arabian Gulf. J. Helminthol. Soc. Wash. 65: 6-9.

123. SEY, O. \& ThATCHER, V.E. (1998): Description of Chiostichorchis lobatotestis sp. n. (Trematoda, Amphistomida) from the spiny rat Mesomys sp. from Brazil. Parasit. Hung. 31: 29-32.

124. Wongsawad, C., Sey, O., Rojanapaibul, A., Chariyahpongpun, P., Suwattanacoupt, S., Marayong, T., WongSAWAD. P. \& ROJTINNAKORN, J. (1998): Trematodes from amphibians and reptiles of Thailand. J. Sci. Soc. Thailand 24: 265-274.

\section{9}

125. Sey, O. \& Wongsawad, C. (1999): Description of Pleurogenes chiangmaiensis n.sp. (Trematoda, Pleurogenidae) from Rana sp. of Thailand. Rivista di Parassitologia 16 (60): 219223.

126. Wongsawad, C., Sey, O., Rojanapaibul, A., Wongsawad, P., Marayong, T.,

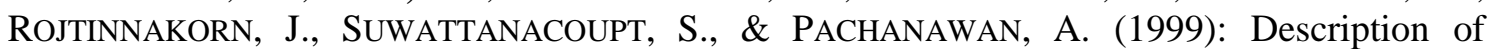
Gorgoderina gracilis sp. n. (Trematoda, Gorgoderidae) from Ichthyophis supachaii TAYLOR, 1960 (Amphibia, Ichthyophiidae) of Thailand. Acta Zool. Hung. 45: 293-297.

127. Ho, J. S., KIM, J. H. \& SEY, O. (1999): New species of Irodes (Copepoda, Taeniacanthidae) parasitic on the goat fish from Kuwait, with a key to the species of Irodes. Pak. J. Marine Sci. 8: $123-129$.

2000

128. SEY, O. \& AL-GHAITH, L. (2000): Helminths of green toads Bufo viridis LAURENTI, 1789 and spiny tailed lizards Uromastyx microlepis BLANFORD, 1874 of Kuwait. Miscnea Zool. Hung. 13: 21-27.

129. Kritsky, D. C., Jimérez-Ruiz, A. F. \& Sey, O. (2000): Diplectinids (Monogenoidae, Dactylogyridae) from the gills of marine fishes of the Persian Gulf off Kuwait. Comp. Parasitol. 67: $145-164$.

130. Ho, J. S., KIM, J. H. \& SEY, O. (2000): Two species of bomolochid copepods (Crustacea) parasitic on marine fishes of Kuwait. Proc. Biol. Soc. Wash. 113: 670-680. 

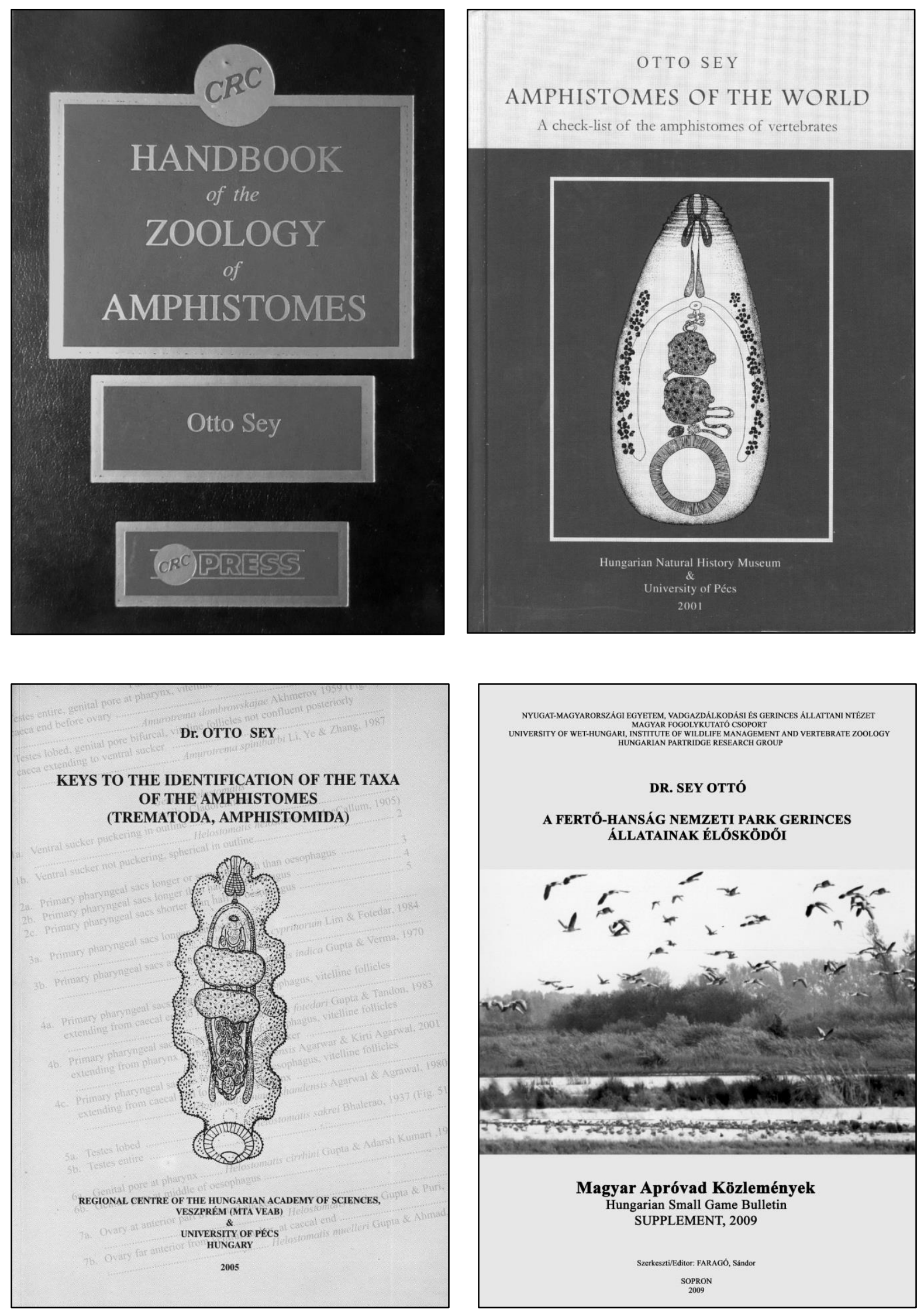

5. ábra: SEY OTTó legfontosabb könyvei

Figure 5: Most important books of OTTÓ SEY 


\section{1}

131. SEY, O. (2001): Amphistomes of the World: A check-list of amphistomes of vertebrates. Hungarian Natural History Museum \& University of Pécs, 368 p.

\section{3}

132. SEY, O., NAhHAS, F. M., UCH, S. \& VANG, C. (2003): Digenetic trematodes from marine fishes of the coast of Kuwait, Arabian Gulf: Fellodistomidae and some smaller families, new host and geographic records. Acta Zoologica Academiae Scientiarum Hungaricae 49 (3):179-200.

\section{4}

133. Wongsawad, C., Rojtinnakorn, J., Wongsawad, P., Rojanapaibul, A., Marayong, T., Suwattanacoupt, S., Sirikanchana, P., Sey, O. \& Jadhav, B. V. (2004): Helmints of Vertebrates in Mae Sa stream, Chiang Mai, Thailand. Southeast Asian J. Trop. Med. Public Health 35 (Suppl.1.): 140-146.

\section{5}

134. SEY, O. (2005): Keys to the identification of the taxa of the Amphistomes (Trematoda, Amphistomatida). Regional Centre of the Hungarian Academy of Sciences (Veszprém) and University of Pécs, $120 \mathrm{p}$.

\section{9}

135. SEY, O. (2009): A Fertö-Hanság Nemzeti Park gerinces állatainak élösködöi. Magyar Apróvad Közlemények - Hungarian Small Game Bulletin. Supplement, 2009. 101 p.

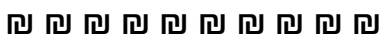

SEY OTTÓ összefoglaló munkái (fajlistái) (SEY, 2001; 2005) alapján összeállíthatjuk az általa leírt, vagy revideált Amphistoma taxonok listáját, ami a tudományban megörökíti az Ö nevét.

E taxonok közül 1 alrend (Zonocotylata SEY, 1987), 1 család (Zygocotylidae SEY, 1988), 4 alcsalád (Travassosiniinae SEY, 1987; Megalodiscinae SEY, 1987; Caballerodiscinae SEY, 1988; Chiorchiinae SEY, 1988), 4 genus (Annelamphistoma THACHER, SEY \& JÉGU, 1996; Inpamphistoma TATCHER, SEY \& JÉGU, 1996; Platycladorchis SEY, 1986; Australodiscus SEY, 1983) 21 pedig faj, az alábbiak szerint:

Alrend: Zonocotylata SEY, 1987

Genus: Annelamphistoma THACHER, SEY \& JÉGU, 1996 Annelamphistoma elegans THACHER, SEY \& JÉGU, 1996

Chiostichorchis lobatotestis SEY \& THATCHER, 1998

Dadayius pacuensis THACHER, SEY \& JÉGU, 1996
(Amphistomida)

(Amphistomida: Cladorchiidae) (Amphistomida: Cladorchiidae)

(Amphistomida: Cladorchiidae)

(Amphistomida: Cladorchiidae) 
Genus: Inpamphistoma TATCHER, SEY \& JÉGU, 1996

Inpamphistoma papillatum TATCHER, SEY \& JÉGU, 1996

Alcsalád: Travassosiniinae SEY, 1987

Neocladorchis multilobularis SEY, 1986

Genus: Platycladorchis SEY, 1986

Platycladorchis microacetabularis SEY, 1986

Platycladorchis macroacetabularis SEY, 1986

Alcsalád: Megalodiscinae SEY, 1987

Stunkardia burti (PRUDHOE, 1944) SEY, 1988

Stunkardia amboinensis (DWIVEDI, 1967) SEY, 1991

Stunkardia stunkardi (TANDON, 1970) SEY, 1991

Alcsalád: Caballerodiscinae SEY, 1988

Caballerodiscus tabascensis (CABALLERO \& SOKOLOFF, 1934) SEY, 1988

(Amphistomida: Cladorchiidae)

Caballerodiscus resupinatus (CABALLERO, 1940) SEY, 1988

Alcsalád: Chiorchiinae SEY, 1988

Genus: Australodiscus SEY, 1983

Australodiscus megalochrus (JOHNSTON, 1912) SEY, 1983

Diplodiscus magnus (SRIVASTAVA, 1934) SEY, 1983

Familia: Zygocotylidae SEY, 1988

Watsonius noci Barrois, 1908) SEY, 1984

Watsonius papillatus SEY, 1984

Carmyerius bulbosus SEY, 1985

Orthocoelium sinuocoelium (WANG, 1959) SEY, 1989

Orthocoelium parastreptocoelium (WANG, 1959) SEY, 1989

Orthocoelium brevicaeca (WANG, 1966) SEY, 1989

Cotylophoron macrosphinctris SEY \& GRABER, 1979

Nilocotyle duplicisphinctris SEY \& GRABER, 1980
(Amphistomida: Cladorchiidae)

(Amphistomida: Cladorchiidae)

(Amphistomida: Cladorchiidae)

(Amphistomida: Cladorchiidae) (Amphistomida: Cladorchiidae) (Amphistomida: Cladorchiidae) (Amphistomida: Cladorchiidae)

(Amphistomida: Cladorchiidae)

(Amphistomida: Cladorchiidae) (Amphistomida: Cladorchiidae)

(Amphistomida: Cladorchiidae)

(Amphistomida: Cladorchiidae)
(Amphistomida: Cladorchiidae)

(Amphistomida: Diplodiscidae)

(Amphistomida: Diplodiscidae)

(Amphistomida: Diplodiscidae)

(Amphistomida)

(Amphistomida: Zygocotylidae)

(Amphistomida: Zygocotylidae)

(Amphistomida: Gastrothylacidae) (Amphistomida: Paramphistomidae) (Amphistomida: Paramphistomidae) (Amphistomida: Paramphistomidae)

(Amphistomida: Paramphistomidae)

(Amphistomida: Paramphistomidae) 

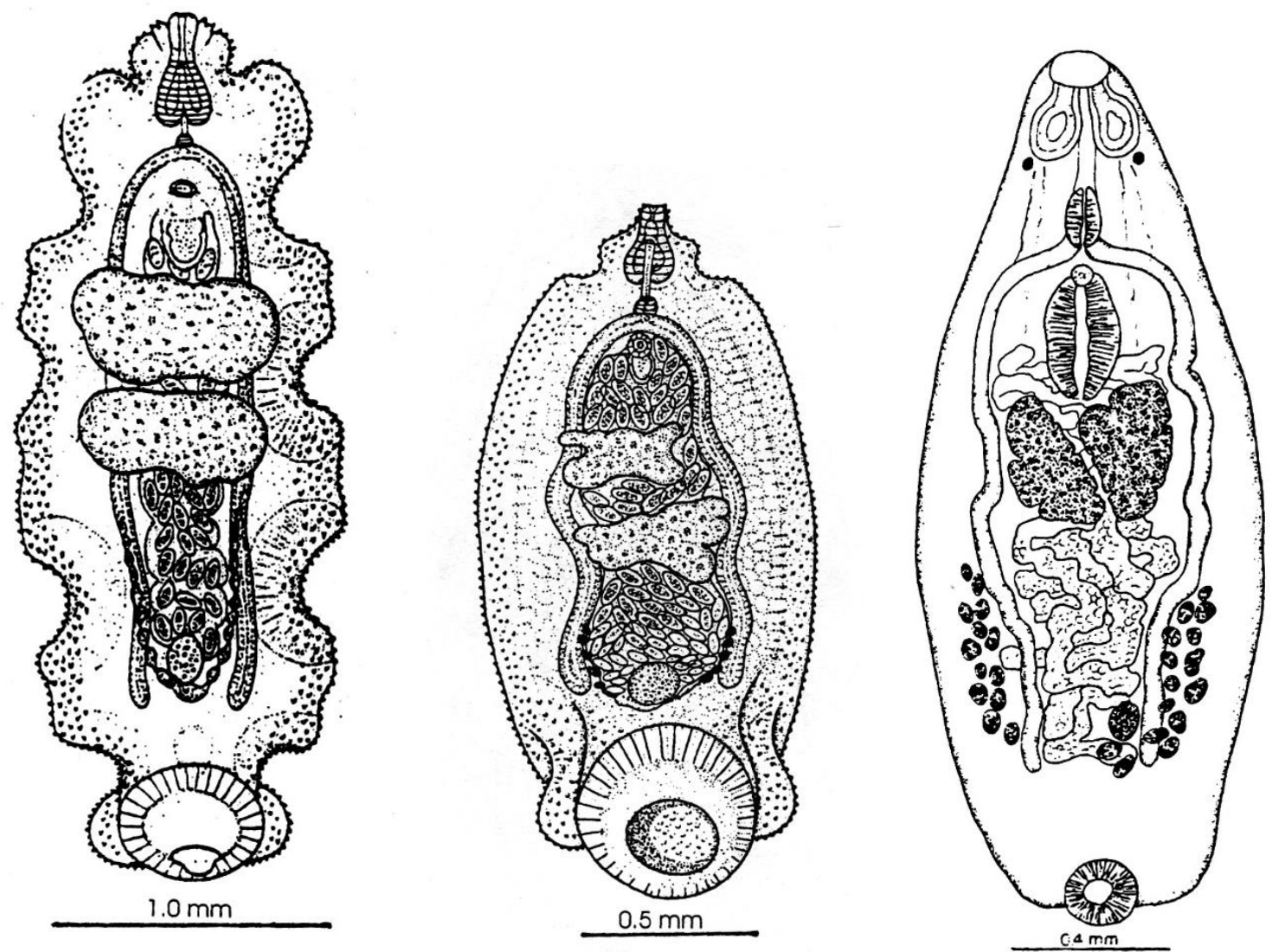

6. ábra: Néhány SEY OTTó által leírt Amphistoma faj: Annelamphistoma elegans THACHER, SEY \& JÉGU, 1996 (bal), Inpamphistoma papillatum TATCHER, SEY \& JÉGU, 1996 (közép), Platycladorchis macroacetabularis SEY, 1986 (jobb)

Figure 6: Some Amphistomes authored by OTTÓ SEY: Annelamphistoma elegans THACHER, SEY \& JÉGU, 1996 (left), Inpamphistoma papillatum TATCHER, SEY \& JÉGU, 1996 (middle), Platycladorchis macroacetabularis SEY, 1986 (right) 
